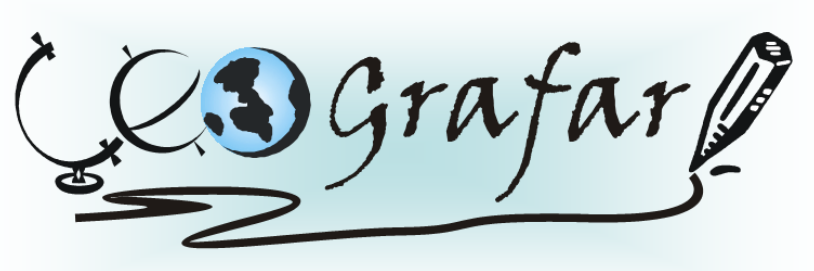

Revista Eletrônica do Programa de Pós-Graduação em Geografia - UFPR

\title{
REVISITANDO OS SIGNIFICADOS DE PAISAGEM À LUZ DAS ABORDAGENS DO PENSAMENTO GEOGRÁFICO
}

\section{REVISITING THE MEANINGS OF LANDSCAPE THROUGH BY APPROACHES OF GEOGRAPHICAL THOUGHT}

(Recebido em 30.09.2014; Aceito em: 04.02.2015)

\author{
Alberto Alexandre Lima de Almeida \\ Prof. Msc. do Instituto Federal de Educação, \\ Ciência e Tecnologia do Rio Grande do Norte \\ Natal, RN, Brasil \\ E-mail: alberto.almeida@ifrn.edu.br
}

\begin{abstract}
RESUMO
A paisagem se constitui num dos conceitos basilares que acompanham o arcabouço teórico da ciência geográfica, desde os seus primórdios até as discussões acadêmicas em nível contemporâneo. Com a sistematização da Geografia enquanto saber científico, a paisagem geográfica adquire uma importância fundamental para essa ciência, confundindo-se, inclusive com o próprio objeto de estudo da Geografia: o espaço geográfico. Esse artigo se propõe a tecer considerações acerca do significado do conceito de paisagem nas diferentes abordagens teóricometodológicas que subsidiaram o pensamento geográfico, a partir de uma leitura crítica das contribuições de autores como Moreira (1982), Santos (1988), Silva (2010), ao mesmo tempo em que busca uma compreensão de paisagem geográfica que estabeleça o diálogo com os novos rumos da ciência geográfica em um mundo cada vez mais globalizado.
\end{abstract}

Palavras-chave: Concepção, Paisagem, Geografia.

\begin{abstract}
The From its prime times through academic discussions and in contemporary level, the landscape is one of the fundamental conceptions that form the theoretical basis of Geography. Along with the systematization of Geography as a scientific
\end{abstract}


knowledge, the geographical landscape acquires such fundamental importance for this science. It is even sometimes confused with its own study subject: geographic space. This article aims at develop some conceptions about the meaning of landscape from different methodological and theoretical approaches which support the geographical understanding. It is based on critical readings on Moreira (1982), Santos (1988), Silva (2010). Also this works focus on comprehending the geographical landscape which can establish a dialogue with the new paths of geographical science in a world even more globalized.

Keywords: Conception, Landscape, Geography.

\section{INTRODUÇÃO}

O presente artigo versa sobre os significados de paisagem presentes no discurso das diversas abordagens do pensamento geográfico e se justifica face à importância da paisagem enquanto conceito-chave para os estudos de natureza geográfica, de tal forma que geógrafos como Siegfried Passarge (1866-1958) e Carl Sauer (1889-1975) consideravam-na como o próprio objeto de estudo da Geografia.

Para percorrermos essa seara, utilizaremos como fio condutor as escolas do pensamento geográfico. Tal percurso se justifica não apenas pelo caráter didático dessa empreitada, mas também pelo fato de essas abordagens expressarem 0 desenvolvimento das forças produtivas e das relações de produção associadas à dinâmica do modo de produção capitalista.

Convém salientar que, em cada momento histórico, diferentes perspectivas filosóficas exerceram influência sobre as escolas do pensamento geográfico. É propósito desse texto ater-se àquelas correntes filosóficas que exerceram uma influência mais incisiva sobre cada uma dessas escolas, tendo em vista as limitações impostas pela própria natureza de um artigo científico.

Nesse sentido, os significados atribuídos ao termo paisagem têm adquirido diferentes conotações ao longo do tempo. A esse respeito, Verdun e Puntel (2010) inferem que a sua concepção tem se diferenciado no tempo, seja como produto das dinâmicas da natureza, seja como produto das relações entre natureza e sociedade.

Atualmente, o estudo da paisagem é considerado como um instrumento primordial para a compreensão do objeto de estudo da ciência geográfica, ou seja, o espaço geográfico. Além disso, o recrudescimento das preocupações de natureza 
ambiental pressupõe a necessidade de se aprofundar os conhecimentos sobre a paisagem, tendo em vista os impactos em seu componente morfológico, o mais perceptível aos sentidos humanos, mediante as ações predatórias do atual estágio de desenvolvimento econômico.

\title{
A PAISAGEM NA ABORDAGEM TRADICIONAL DA GEOGRAFIA
}

A origem do termo paisagem remonta ao século $\mathrm{XV}$, derivado do termo holandês landskip, do qual é originário o vocábulo alemão landschaft, bastante utilizado pelos geógrafos alemães, quando da sistematização da Geografia como saber científico, no início do século XIX. O termo alemão landschaft foi desenvolvido inicialmente por Humboldt (1845-1926) e, posteriormente, por Dokuchaev (18461903), Passarge (1866-1958) e Berg (1876-1950) e designava, sobretudo, a interação entre os elementos naturais. A esse respeito, Rodriguez (2002, p.96) infere que

\begin{abstract}
A noção de paisagem, designada com o termo alemão Landschaft foi desenvolvida por Humboldt e posteriormente pelos sábios Dokuchaev, Passarge e Berg no século XIX e nos primeiros anos do século XX. Esta visão tinha uma acepção fortemente natural. O conteúdo dessa noção expressava a ideia da interação entre todos os componentes naturais (rocha, relevo, clima, água, solo e vegetação) e um espaço físico concreto.
\end{abstract}

Da antiguidade clássica até o século XVIII, a Geografia terá sua imagem associada a um levantamento sistemático de terras e povos através de relatos de viagens ou, ainda, de relatórios estatísticos de órgãos administrativos. Dessa forma, esse período se caracteriza como uma fase de dispersão do conhecimento geográfico, constituindo-se na fase pré-científica da Geografia. Nesse caso, tratavase da compilação de um "conhecimento geográfico", configurado num tratado descritivo e cartográfico com o caráter de auxiliar a administração do Estado.

As premissas que levaram à institucionalização da Geografia no século XIX estão ligadas ao processo de desenvolvimento do capitalismo. A ascensão desse modo de produção provoca transformações no pensamento filosófico e político, ao mesmo tempo em que opera modificações na instância econômica e política. De acordo com Moraes (2005, p.57): 
Os pressupostos históricos e as fontes de sistematização geográfica se forjaram no período da transição, na fase 'heroica' da burguesia, em que esta classe agia e pensava no sentido de transformar a ordem social existente. Sua luta contra os resquícios do modo de produção feudal dava um conteúdo progressista à sua prática e ao seu pensamento.

Entre essas premissas convém destacar a expansão marítima europeia, o desenvolvimento das técnicas cartográficas e a concepção antropocêntrica de mundo. Enquanto as duas primeiras possibilitaram o acúmulo e a representação de informações sobre os diferentes pontos da Terra, essa última viabilizou a valorização da razão humana como instrumento para a explicação dos fenômenos. Desta forma, essa tríade criará as condições precípuas para o surgimento da geografia moderna, conforme ressalta Pereira (2009, p. 81):

A grande revolução para o conhecimento geográfico começa a ser preparada a partir da extraordinária expansão do espaço conhecido, do domínio da configuração da Terra e do desprezo às ideias e crenças a respeito da superfície terrestre que advém com a Idade Moderna.

Nesse contexto, a Geografia será filha dessas transformações, viabilizadas pela expansão do capitalismo na Europa, conforme atestam Pereira (2009), Moraes (2005) e Gomes (1996). Será na Alemanha, no início do século XIX, que a Geografia moderna será sistematizada, ganhando ares de cientificidade e reconhecimento acadêmico, como condição necessária para atender os interesses políticos e econômicos que despontam no cenário daquela nação, naquele determinado momento histórico. Os interesses estavam voltados para a resolução de dois problemas que se configuravam como um entrave para o desenvolvimento do capitalismo em solo alemão: a inexistência de um Estado nacional, o que se traduzia na falta de um centro organizador do espaço que se convertesse em ponto de convergência das relações econômicas; e a situação de atraso da Alemanha em relação às demais nações europeias. Segundo Pereira (2009, p. 107-108):

A questão da unificação se coloca então como parte de um projeto político e econômico dos que pretendem a hegemonia no interior da Alemanha, como uma condição para o avanço do capitalismo que vê no nacional a possibilidade de realizar o universal. A geografia, portanto, nasce para responder a duas necessidades básicas: a unificação do território e a 
conquista de um lugar privilegiado para a Alemanha no conjunto das demais nações.

É nesse cenário que a Geografia será alçada ao status de ciência, entre o final do século XVIII e início do século XIX. Para tal, foram decisivas as contribuições de Humboldt (1845-1926) e Ritter (1779-1859), considerados como os sistematizadores da Geografia Moderna. Com eles, a Geografia torna-se um saber acadêmico, produzido a partir de centros universitários e ensinado nas escolas.

Com uma metodologia alicerçada no empirismo, Humboldt apud Moraes (2005) concebia a Geografia "como uma espécie de síntese dos conhecimentos relativos à Terra". Nesse sentido, reconhecia-se uma unidade na imensa diversidade dos fenômenos alusivos ao nosso planeta. Para atingir tal objetivo, o geógrafo deveria se utilizar do método empírico, a partir da observação da paisagem. A esse respeito, Moraes (2005) infere que a paisagem causaria no observador uma impressão, a qual, combinada com a observação sistemática dos seus elementos componentes e filtrada pelo raciocínio lógico, levaria à explicação: a causalidade das conexões contidas na paisagem observada.

A preocupação com a tentativa de estabelecer formulações teóricas sobre a relação entre o homem e o meio era a tônica da produção de Hitter. Dessa forma, Hitter apud Tonini (2006) "interpretava a natureza como elemento determinante para o desenvolvimento histórico dos povos". Noutras palavras, a identidade e destino dos povos seriam explicados por leis naturais.

Humboldt e Ritter lançaram as bases do que veio a se configurar como primeira corrente de pensamento da abordagem tradicional da Geografia: o determinismo geográfico alemão, cujo maior expoente foi Friedrich Ratzel (18441904). Ele introduzirá no discurso geográfico a concepção naturalista do desenvolvimento da sociedade humana. Segundo Sodré (1986, p. 49):

Ratzel via o homem como produto final de uma evolução cuja principal forma era a seleção natural dos tipos, na conformidade da capacidade de se ajustarem ao meio natural. Ele tendia a ver o homem como produto de seu meio, moldado por ele, vencendo na proporção de sua adaptação a esse meio.

Embora reconheça a ação do homem sobre o meio, Ratzel coloca o ser humano no papel de coadjuvante desse processo. Ele é considerado uma variante a mais na descrição da paisagem, similarmente ao clima, relevo, vegetação ou 
hidrografia. Dessa forma, a paisagem era vista como um conjunto de relações de fatos naturais, associados às formas visíveis sobre a superfície da Terra. Essa concepção de paisagem vai ao encontro da teoria do espaço vital, o qual serviu para legitimar os esforços do imperialismo germânico em promover a unificação alemã e a expansão do território. A esse respeito, Moreira atesta $(1981$, p. 33) que

O Estado é a expressão orgânica do 'determinismo geográfico'. O Estado é um organismo em parte humano e em parte terrestre. É a forma concreta que adquire em cada canto a relação homem-meio, poder-se-ia dizer. A própria síntese. O Estado é assim porque possui uma relação necessária com a natureza: do espaço é que retira sua existência e desenvolvimento. Os Estados necessitam de espaço, como as espécies, por isto lutam pelo seu domínio como as espécies. A subsistência, energia, vitalidade e o crescimento dos Estados têm por motor a busca e conquista de novos espaços.

O conceito de paisagem da escola alemã, fundamentada no positivismo, aparece como uma associação de múltiplos fenômenos, o que conferiu à Geografia o estigma de "ciência de síntese". A esse respeito, Moraes (2005, p.32) enfatiza que

Esta perspectiva apresenta duas variantes para a apreensão da paisagem: uma, mantendo a tônica descritiva, se determinaria na enumeração dos elementos presentes e na discussão das formas-daí ser denominada de morfológica. A outra se preocuparia mais com a relação entre os elementos e com a dinâmica destes, apontando para um estudo de fisiologia, isto é, do funcionamento da paisagem.

Assim, o discurso determinista da Geografia colocava o ser humano como coadjuvante na natureza. Era ela (a natureza) quem prescrevia os dispositivos para se compreender as características e peculiaridades dos grupos humanos. A esse respeito, Tonini (2006) infere que a paisagem geográfica apresentava determinada configuração devido à presença a priori dos elementos naturais (relevo, clima, vegetação, hidrografia, homem) e que a maneira de eles interagirem era o que dava condições para o surgimento de determinada paisagem geográfica.

Em síntese, os estudos da paisagem estavam, inicialmente, muito preocupados em descrever as formas físicas da superfície terrestre. Contudo, mesmo entre os geógrafos alemães do século XIX, começam a ocorrer estudos focados na relação entre o homem e o ambiente, daí a separação entre "paisagens naturais" e "paisagens culturais". Segundo Moraes (2005), o próprio Ritter, em sua 
obra Geografia Comparada, tinha como objetivo o estudo antropocêntrico da Terra, relacionando homem e natureza.

Porém, é a "escola possibilista" francesa, ainda que fundamentada no positivismo e no empirismo, que dará uma ênfase maior ao homem, na medida em que alça o ser humano à condição e à possibilidade de modificar o meio. A sua origem remonta ao legado produzido pela derrota francesa na guerra francoprussiana (1870). Ela surge para servir aos interesses do estado francês em promover a recuperação dos territórios perdidos nessa guerra e para municiar fundamentos que legitimassem o expansionismo colonial da nação. Contextualizando o surgimento da Geografia acadêmica francesa, Moreira (1981, p. 34) enfatiza que

A 'escola francesa', portanto, nasce do clima produzido pela derrota da França perante a Alemanha prussiana na guerra de 1870. Surge, a um só tempo, para servir à burguesia francesa em seu afã de recuperação de perdas territoriais com a guerra e sua compensação com maior expansão colonial. Domesticamente, visa ainda a servir de instrumento de recuperação da imagem de grande potência, abalada pela guerra.

O maior expoente da escola possibilista francesa foi Vidal de La Blache (1845-1918). Esse geógrafo criticou a minimização do homem pela escola alemã, argumentando que competia à análise geográfica o estudo do resultado da ação humana na paisagem. Para Morais (2005, p. 81), La Blache "definiu o objeto da Geografia como a relação homem-natureza, na perspectiva de paisagem". Dessa forma, o homem passa a ser visto como um ser ativo, que sofre a influência do meio, porém que atua sobre este, podendo transformá-lo.

Assim, na perspectiva vidaliana, a paisagem adquire um certo caráter de funcionalidade, comportando-se como se fosse um organismo, pois, conforme afirma Gomes (1996, p. 198):

A terra, a paisagem, a região, as nações, a cidade, etc. eram todas concebidas como organismos. Nem a escala, nem o tipo de fenômeno eram importantes; quer ele fosse essencialmente natural (paisagem não humanizada), quer fosse humano, poderia sempre ser considerado como um organismo.

$\mathrm{Na}$ escola francesa, e em La Blache particularmente, a Geografia torna-se claramente antideterminista, passando a observar as relações mútuas entre o 
homem e o ambiente físico. Nesse contexto, a natureza passa a ser vista como possibilidades para a ação humana. É justamente a forma de o homem se relacionar com a natureza que propiciará o surgimento de diferentes paisagens. Segundo Tonini (2006, p. 52), "é dessa relação entre os grupos humanos e os recursos disponíveis no meio que surgirá a configuração da paisagem".

Desse modo, as diferenças entre o determinismo e o possibilismo geográfico não diziam respeito à questão do método, pois mesmo colocando pesos diferentes no homem e na natureza em seus estudos científicos continuavam reféns do positivismo e do empirismo. A esse respeito, Tonini (2006, p. 54) enfatiza que

\footnotetext{
Nesse sentido, a análise da paisagem geográfica estava muito presa às explicações do visível, ou seja, a uma matriz e estética que colocava o olhar apenas sobre o resultado da ação dos grupos humanos na paisagem natural. Suas análises ficavam presas, assim, ao mundo das aparências.
}

Dessa forma, as divergências entre essas duas escolas geográficas eram insuficientes para promover uma ruptura com a filosofia positivista, estando ambas limitadas pelos aspectos descritivos dos fenômenos.

A terceira grande escola da Geografia Tradicional, denominada por alguns estudiosos de racionalista, tem em Carl Sauer (1889-1995) um de seus maiores expoentes. Para ele, a Geografia deveria ser capaz de explicar os aspectos morfológicos que estruturam o espaço e sua evolução no tempo. Nesse sentido, os geógrafos deveriam conduzir-se de uma maneira analítica para examinar os elementos significativos na estruturação de uma paisagem, a qual não poderia ser explicada apenas a partir de um viés meramente descritivo.

Abordando as contribuições desse geógrafo para o estudo da paisagem, Gomes (1996) infere que a paisagem concebida por Sauer era fruto de uma associação entre formas físicas e culturais, constituindo o resultado de um longo processo de constituição e diferenciação de um espaço. É nesse contexto que ganha visibilidade a separação entre paisagem natural e paisagem cultural, sendo esta última, de acordo com Sauer, o verdadeiro objeto de estudo da ciência geográfica.

Em que pesem as especificidades de cada escola da abordagem tradicional do pensamento geográfico, elas tinham em comum o apego exacerbado ao 
empirismo, limitado por uma análise descritiva dos fenômenos, em que o fundamento filosófico positivista servia de base para os estudos geográficos.

\section{A PAISAGEM E O MOVIMENTO DE RENOVAÇÃO DA GEOGRAFIA}

A partir da segunda metade do século $X X$, vão se abrir caminhos para novas discussões e se propor novas posturas metodológicas para lidar com essa ciência, de tal forma que a Geografia Tradicional é alvo de um processo de crítica. Essas críticas dizem respeito não apenas à indefinição do objeto de análise da ciência geográfica, mas também à questão do método e do fundamento filosófico que lhe davam suporte. Dessa forma, o chamado "movimento de renovação da Geografia" iria consolidar-se nas décadas seguintes, até tornar-se hegemônico no final dos anos 70 do século passado.

Essas mudanças, que não se limitaram apenas à ciência geográfica, expressam um novo arranjo da superestrutura político-ideológica face aos novos ditames impostos pela passagem da fase concorrencial do capitalismo para a sua fase monopolista, no qual o avanço das forças produtivas exige uma reorganização de todas as instâncias do modo de produção capitalista.

Sob a égide do capitalismo monopolista, o mundo é assolado por céleres transformações que irão impactar sobremaneira no pensamento tradicional da Geografia. A expansão das empresas multinacionais, o avanço tecnológico, o keynesianismo são sintomas de uma nova forma de se reorganizar o espaço, os quais refutam os postulados positivistas que alicerçavam essa ciência. Nesse contexto, a observação lógico-concreta vai sendo substituída pela análise abstrata, com base na matemática e na estatística; o levantamento de campo cede espaço às técnicas de sensoriamento remoto, conforme preconiza Moreira (1982, p. 46):

\footnotetext{
A 'revolução' na matemática, favorecendo a revolução mais ampliada da tecnologia, com o desenvolvimento dos computadores, dotará o capital de um poder sobre a natureza, os homens e os espaços até então não atingido. Permitirá uma notável precisão de movimentos sobre o espaço mundial. Vale dizer, seu mapeamento em caráter mais rigoroso. Daí a 'revolução' na geografia.
}

As grandes empresas e o Estado agora lançavam mão do planejamento para gerir os lucros e regular a vida econômica. Além disso, a elevada urbanização e 
industrialização revelavam um novo grau de complexidade no arranjo espacial, cujos maiores reflexos eram a mecanização do campo e a formação de megalópoles. A respeito dessas transformações, Moraes (2005, p. 104) ressalta que

\begin{abstract}
O lugar já não se explicava em si mesmo; os centros de decisão das atividades ali desenvolvidas localizavam-se, muitas vezes, a milhares de quilômetros. O espaço terrestre se globalizara nos fluxos e nas relações econômicas. Vivia-se o capitalismo das empresas multinacionais, dos transportes e das comunicações interoceânicas. A realidade local era apenas elo de uma cadeia que articulava todo o planeta.
\end{abstract}

Nessa perspectiva, o instrumental de pesquisa da Geografia Tradicional não dava mais conta de explicar um mundo no qual a apreensão dos fenômenos escapava aos limites do local e estavam inseridos num contexto mais globalizado. Sendo assim, o levantamento de campo passa a ceder espaço para novas técnicas de análise do espaço geográfico, notadamente aquelas vinculadas à cibernética e ao sensoriamento remoto.

A transferência da hegemonia econômica mundial da Europa para os Estados Unidos vai justificar a gênese desse movimento em solo norte americano. A new Geography vai se fundamentar num discurso que se contrapõe à "velha Geografia", sistematizada em solo europeu. É a força do capitalismo americano estendendo os seus tentáculos sobre a superfície do planeta; e é a escola geográfica americana, a Geografia Pragmática, que lançará as bases do movimento de renovação da Geografia.

A primeira vertente desse movimento de renovação da ciência geográfica é a chamada "Geografia Pragmática". Suas maiores críticas à Geografia Tradicional dizem respeito ao seu caráter não prático, ou seja, tratava-se de uma ciência inoperante e que não intervinha na realidade. Sendo assim, vai propor uma ruptura metodológica com o positivismo clássico, centrado no concreto e na observação direta, apontando para a perspectiva de se instituir uma ciência aplicada, com base no neopositivismo.

Segundo a Geografia Pragmática, todo o temário da ciência geográfica poderia ser explicado mediante a utilização de métodos matemáticos. De acordo com essa premissa, qualquer fenômeno geográfico poderia ser expresso em termos numéricos e compreendido através de cálculos, graças ao emprego da estatística e da computação como ferramentas imprescindíveis para a explicação geográfica. 
Nesse sentido, o desenvolvimento das técnicas, a utilização de métodos estatísticos e da teoria geral dos sistemas vai estabelecer a tônica das pesquisas em Geografia, as quais, via de regra, visam atender as novas tarefas impostas pelo planejamento, sejam de empresas privadas ou de órgãos governamentais.

Nesse contexto, não basta enumerar os elementos constitutivos da paisagem, é necessário submetê-los aos filtros da matemática e da estatística, com o intuito de se obter médias, índices, variáveis ou modelos, os quais dariam os subsídios para explicar o espaço geográfico. No tocante aos novos paradigmas advindos com a Geografia Pragmática, Moreira (1982, p. 44-45) argumenta que

\begin{abstract}
Assim, em vez da descrição da paisagem, toma seu lugar a matematização da paisagem. Em vez da descrição da morfologia da paisagem, toma seu lugar uma rigorosa tipologia de padrões espaciais. Em vez da pesquisa de campo, toma seu lugar o computador. Em vez da descrição subjetiva, toma seu lugar a objetividade descritiva da linguagem matemática.
\end{abstract}

Todavia, é a vertente crítica do movimento de renovação da Geografia que dominará o cenário dessa ciência, a partir das últimas décadas do século passado. Mesmo não se constituindo numa concepção monolítica de propostas, devido ao mosaico de orientações metodológicas que abrangem, a(s) Geografia(s) crítica(s) se caracteriza $(m)$ pelo combate às segregações sociais e espaciais contidas no espaço geográfico, bem como pelo rompimento da articulação do discurso geográfico com o Estado e com as classes dominantes.

O movimento de renovação da chamada Geografia Crítica está relacionado aos movimentos sociais que se alastraram pela Europa e pelo mundo a partir da década de 60 do século $X X$, entre os quais destacamos as revoltas de maio de 1968, a consolidação de revolução cubana e a guerra do Vietnã, os quais são exemplos de acontecimentos que puseram em xeque o modelo de sociedade legitimado pelo modo de produção capitalista.

Nesse contexto, e tendo como referência o questionamento da práxis políticoideológica e científica dessa disciplina, surgem geógrafos de inspiração marxista que, a partir das premissas do materialismo histórico e dialético, vão incorporar aos estudos geográficos temas até então ignorados por essa ciência. Dessa forma, passam a fazer parte da análise geográfica categorias como: modo de produção, 
capital, mais-valia, trabalho assalariado, etc. A esse respeito, Silva (1989, p. 7-8) reitera que

\begin{abstract}
A [Geografia] crítica mostra que a relação homem/meio é uma relação determinada pelo capital e como qualquer relação capitalista é uma relação de troca, troca desigual; uma relação de dominação mediada pelo trabalho alienado, porque é um trabalho abstrato; um trabalho separado do sujeito. $\mathrm{O}$ capitalista compra a força de trabalho numa relação de troca que se dá circulação. Na verdade, ele está comprando horas de trabalho que essa força vai colocar em funcionamento e se apropria de horas de trabalho não pago porque o capitalista coloca a força de trabalho para trabalhar durante mais tempo do que é necessário para a reprodução do seu valor, que corresponde ao trabalho necessário, ao trabalho pago, que formalmente o capitalista paga sob a forma de salário.
\end{abstract}

Assim sendo, os conteúdos da Geografia passaram a ser vistos sob a ótica da totalidade que envolve a inter-relação entre sociedade, natureza, trabalho e cultura, em que o espaço geográfico, como produto/processo social, é repleto de lutas, conflitos, contradições e desigualdades. Essa perspectiva analisa o espaço geográfico a partir das suas relações de poder, em que a base econômica, dialeticamente articulada às instâncias político-ideológicas, organiza territorialmente a sociedade. Segundo Silva (2010, p. 116), o espaço geográfico é "o espaço dos homens e confunde-se com a própria sociedade e, como ela, é também uma materialidade histórica".

No que diz respeito à paisagem, a Geografia Crítica a considera como um produto-processo das formas de produção do espaço, isto é, cada tipo de paisagem representa diferentes níveis de forças produtivas, materiais e imateriais, de acordo com a sucessão histórica dos modos de produção.

Nesse sentido, a paisagem, na abordagem crítica da Geografia, deve se constituir como ponto de partida dos estudos geográficos e não como objeto final desses estudos. Ela seria, juntamente com a concepção de lugar, os conceitos basilares para o entendimento do objeto de estudo da Geografia: o espaço geográfico. É através da observação da paisagem que fazemos as nossas primeiras indagações com vistas à compreensão do espaço geográfico. Silva (2010, p. 117) ressalta que "a paisagem tem 'o apresentar-se' que os sentidos (principalmente a visão) apreende, mas tem uma essência que só o entendimento explica".

Para Santos (1988), a paisagem é o conjunto de formas que, num dado momento, exprimem as heranças que representam as sucessivas relações 
localizadas entre homem e natureza. Ela está sempre em movimento, é sempre objeto de mudança. A respeito da mutabilidade da paisagem, Santos (1988, p. 24) afirma que

\begin{abstract}
A paisagem tem, pois, um movimento que pode ser mais ou menos rápido. As formas não nascem apenas das possibilidades técnicas de uma época, mas dependem, também, das condições econômicas, políticas, culturais, etc. A técnica tem um papel importante, mas não tem existência histórica fora das relações sociais. A paisagem deve ser pensada paralelamente às condições políticas, econômicas e também culturais. Desvendar essa dinâmica social é fundamental; as paisagens nos restituem todo um cabedal histórico de técnicas cuja era revela, mas ela não mostra todos os dados, que nem sempre são visíveis.
\end{abstract}

Ainda seguindo essa linha de raciocínio, Cavalcanti (1998) enfatiza que o conceito de paisagem deve aparecer no primeiro nível de análise do lugar e deve se constituir como um conceito-chave para a compreensão do espaço geográfico. Para essa autora, é importante considerar a dimensão objetiva e subjetiva da paisagem e de sua construção.

Também alicerçado no materialismo histórico e dialético, Carvalho (1994, p.99) enfatiza que "as paisagens devem ser encaradas como verdadeiros laboratórios, onde as marcas dos processos pretéritos se farão presentes, entrarão em choque com processos atuais e determinarão processos futuros". Nesse sentido, as paisagens são constantemente modificadas e o trabalho humano é o principal agente dessas mudanças.

Portanto, a partir das contribuições da abordagem crítica da Geografia, a paisagem deixa de ser constituir como fenômeno a-histórico, desvendado pela simples descrição de suas características, passando a ser reconhecida como algo dinâmico, resultante de processos naturais e sociais.

\title{
AS ABORDAGENS CONTEMPORÂNEAS DA GEOGRAFIA E A PAISAGEM
}

A partir do final da década de 80 do século passado, surge no horizonte da Geografia a corrente conhecida como "Nova Geografia Cultural". Em que pese o discurso cultural da Geografia já estar presente na obra de Sauer (1889-1975), o seu reaparecimento está articulado à intensificação do processo de globalização verificado nas últimas décadas do século $\mathrm{XX}$, o qual apresenta como características: 
o fim da guerra fria, o recrudescimento dos fluxos migratórios e a intensificação dos movimentos ecológicos, entre outros. Com a globalização, acentua-se a preocupação com as diferentes práticas culturais e a resistência à tendência em homogeneizá-las.

Diferentemente da tradição saueriana de cultura, a perspectiva contemporânea da geografia cultural apresenta preocupações com a temática social. Correa e Rosendhal (2011, p. 13) atestam que "a cultura, por outro lado ainda, se é considerada como sendo o conjunto de saberes, técnicas, crenças e valores, este conjunto, entretanto, é entendido como sendo parte do cotidiano e cunhado no seio das relações sociais de uma sociedade de classes". Nessa revisão, a cultura deixa de ser vista como fenômeno alheio às condições materiais de existência.

Procurando aproximar as formulações do materialismo histórico e dialético dos princípios da Nova Geografia Cultural, Cosgrove (2011, p. 118) ressalta que

\begin{abstract}
Para nossa compreensão de cultura corresponder à evidência da prática precisamos voltar à noção de modo de produção como um modo de vida, incorporando a cultura dentro da produção humana, ligada em igualdade dialética com a produção material de bens. A consciência humana, ideias e crenças são parte do processo produtivo material (grifo do autor).
\end{abstract}

No que concerne à paisagem, a Nova Geografia Cultural segue uma linha interpretativa que a concebe como um texto a ser lido e interpretado como documento social, a partir de uma configuração de símbolos e signos. Nessa ótica, os estudos sobre a paisagem se colocam numa perspectiva que prioriza 0 subjetivismo como uma construção mental a partir da percepção e vivência no território. Cosgrove \& Jackson (2011, p. 137) ressaltam que nos estudos recentes de Geografia cultural, "o conceito de paisagem é, ele próprio, um modo especial de compor, estruturar e dar significado a um mundo externo, cuja história tem que ser entendida em relação à apropriação material da terra".

Outra abordagem que ganhou importância nas décadas finais do século passado diz respeito à chamada "Geografia Humanística". Mesmo buscando referências variadas, o que denuncia um certo ecletismo de concepções, o horizonte humanístico da Geografia apresenta, pelo menos, duas premissas que 0 caracterizam. 
Primeiramente, o espaço é visto como um lugar repleto de significações variadas, o que confere um enfoque de subjetividade na análise geográfica; e, em segundo lugar, evidencia-se a valorização da arte como elemento de mediação entre a vida e o universo das representações. Nessa perspectiva, Tuan (1982, p. 143) infere que a Geografia Humanística "procura um entendimento do mundo humano através do estudo das relações das pessoas com a natureza, do seu comportamento geográfico, bem como dos seus sentimentos e ideias a respeito do espaço e do lugar".

Em segundo lugar, no discurso humanístico da Geografia, no qual se sobressai a abordagem fenomenológica, a paisagem passa a ser um território visto e sentido, e cada vez mais subjetivo e elaborado pela mente. Nesse caso, ela não deve ser encarada apenas como um objeto de estudo, refletido e interpretado intelectualmente, mas como uma forma de vivência na sua plena positividade do cotidiano das pessoas. Noutros termos, a paisagem pode ser considerada um texto que serve a uma multiplicidade de leituras.

Essa abordagem humanística da Geografia incorpora a concepção de "espaço vivido" em seus estudos. Nesses termos, ele deve ser compreendido como um espaço de vida, construído e representado pelos atores sociais que nele circulam. De acordo com Gomes (1996, p. 317), "o espaço vivido torna-se uma categoria que acentua a constituição atual dos lugares, dedicando uma atenção especial às redes de valores e de significações materiais e afetivas".

Portanto, para a abordagem humanística da Geografia, a subjetividade e representatividade da paisagem geográfica conferem um rol de significados, os quais podem ser apreendidos e sentidos a partir de individualizados modos de promover a leitura do mundo.

Em suma, no atual cenário da ciência geográfica encontramos diferentes abordagens teórico-metodológicas, as quais coexistem sem que se possa admitir a hegemonia de alguma delas no meio acadêmico. Inspiradas no positivismo, na fenomenologia ou no materialismo histórico e dialético, entre outras correntes filosóficas, essas abordagens expressam o pluralismo de ideias que caracterizam o mundo contemporâneo, no qual o próprio modelo de ciência vigente é relativizado, mediante inquietudes a respeito de sua própria racionalidade. 


\section{CONSIDERAÇÕES FINAIS}

A paisagem é um produto/processo da materialização da relação sociedadenatureza, na qual estão impressas as marcas do desenvolvimento das forças produtivas e as dimensões político-culturais subjacentes à dinâmica dos modos de produção. Nesse sentido, admitimos que a paisagem apresenta um componente morfológico, mas que só pode ser compreendido, em sua essência, a partir de uma análise que não abdique do processo histórico que a configurou, em meio ao qual se sobressaem aspectos econômicos, sociais, políticos e culturais como componentes de um arranjo estrutural de um determinado modo de produção.

Dessa forma, a paisagem é, ao mesmo tempo, forma, produto, processo e função que se apresentam com significados diferentes face ao momento histórico em que estão inseridos, no qual se articulam, dialeticamente, componentes naturais, sociais, políticos, econômicos e culturais.

Ao longo da trajetória da produção do conhecimento geográfico, a paisagem se constituiu como uma importante categoria de análise para a ciência geográfica, independentemente da abordagem teórico-metodológica hegemônica em cada momento histórico. Ela representa um elemento de extrema importância para a compreensão da complexidade do espaço geográfico, tendo em vista se constituir no primeiro elemento de apreensão para se compreender a dinâmica desse espaço. Além de se apresentar como um conceito-chave para a interpretação dos fenômenos geográficos, a paisagem é o resultado da vida das pessoas e da transformação da natureza face aos processos produtivos e às dinâmicas das relações de trabalho.

\section{REFERÊNCIAS}

CARVALHO, Marcos B. de. A natureza da Geografia no ensino médio. In: OLIVEIRA, Ariovaldo U. de. (org.). Para onde vai o ensino de Geografia. 5. ed. São Paulo: Contexto, 1994.

CAVALCANTI, Lana de S. Geografia, escola e construção de conhecimentos. Campinas: Papirus, 1998. 
CORREA, Roberto L.; ROSENDHAL, Zeny. Geografia cultural: introduzindo a temática, os textos e uma agenda. In: ed. Rio de Janeiro: Bertrand Brasil, 2011. 5. ed. Introdução à Geografia cultural. 5.

COSGROVE, Denis E. Em direção a uma Geografia cultural radical. In: CORREA, Roberto L.; ROSENDHAL, Zeny. (orgs.). Introdução à Geografia cultural. 5. ed. Rio de Janeiro: Bertrand Brasil, 2011.

COSGROVE, Denis E.; JACKSON, Peter. Novos rumos da Geografia cultural. In: CORREA, Roberto L.; ROSENDHAL, Zeny. (orgs.). Introdução à Geografia cultural. 5. ed. Rio de Janeiro: Bertrand Brasil, 2011.

GOMES, Paulo C. da C. Geografia e modernidade. Rio de Janeiro: Bertrand Brasil, 1996.

MORAES, Antônio C. R. Geografia: pequena história crítica. 20. ed. São Paulo: Annablume, 2005.

MOREIRA, Ruy. O que é Geografia. 2. ed. São Paulo: Brasiliense, 1982. (Coleção primeiros passos).

PEREIRA, Raquel M. F. Da Geografia que se ensina à gênese da Geografia moderna. 4. Ed. Florianópolis: Ed. da UFSC, 2009.

RODRIGUEZ, José M. M. A classificação das paisagens a partir de uma visão geossistêmica. Mercator, Fortaleza, ano I, n. 1, 2002.

SANTOS, Mílton. Metamorfoses do espaço habitado. São Paulo: Hucitec, 1988.

SILVA, Lenira R. da. Do senso comum à Geografia científica. 2. ed. São Paulo: Contexto, 2010.

A não espacialidade geográfica e a questão da terra. Natal: Ed. Universitária, 1989. (Coleção Sala de aula).

SODRÈ, Nélson W. Introdução à Geografia: Geografia e ideologia. 2. ed. Petrópolis: Vozes, 1977.

TONINI, Ivaine M. Geografia escolar: uma história sobre seus discursos pedagógicos. 2. ed. ljuí: Ed. Unijuí, 2006.

TUAN, Yi- Fu. Geografia humanística. In: CHRISTOFOLETTI, Antônio (org.). Perspectivas da Geografia. São Paulo: DIFEL, 1982.

VERDUN, Roberto; PUNTEL, Geovani A. Espaço geográfico e paisagem. In: BUITONI, Marisa (org.) Geografia: ensino fundamental. Brasília: MEC/SEB, 2010. (Coleção Explorando o Ensino). 